\title{
Argumentation Skills: An Analysis on EFL Students' Essays Based on Toulmin's Model of Argument
}

\author{
Jumariati $^{1 *}$, Emma Rosana Febriyanti ${ }^{2}$, Muhammad Rizki $^{3}$ \\ ${ }^{1}$ Lambung Mangkurat University* \\ ${ }^{2}$ Lambung Mangkurat University \\ ${ }^{3}$ English First Banjarmasin \\ *Corresponding author. Email: jumariati01@ulm.ac.id
}

\begin{abstract}
Writing argumentative essays is not only challenging because the writers must have adequate knowledge on the topic but also, they must provide strong arguments to convince the readers. This study analyzes the argumentation skills of advanced level students in writing the content of an argumentative essay. The design of the research was descriptive quantitative involving 60 argumentative essays written by 30 students of the Academic Writing course. The data were analyzed by using a scoring guide referring to Toulmin's model of argumentation. The analysis found that the mean score is 14.29 which is considered as good. However, further analysis on the argumentation elements of students' essays shows that the use of opposition and refutation is low as there are $40 \%$ of students in the first writing and $20 \%$ of students in the second writing did not propose any opposing argument. Furthermore, $46.66 \%$ of the students in the first writing and $50 \%$ students in the second writing did not give any refutation in their essays. Referring to the findings, it is suggested that more practices should be given to develop students' argumentation skills. Further research is also recommended to investigate argumentation skills by involving more subjects and different methods of analysis to reveal more comprehensive findings.
\end{abstract}

Keywords: model of argumentation, Toulmin's Model, content, essay writing.

\section{INTRODUCTION}

Students often consider writing as the most challenging skill as it requires them to possess linguistic knowledge, master the vocabulary and syntactic patterns and good ability in using cohesive devices [10,22] Studies have found that writing good essays is challenging for EFL students as they had problems in organizing ideas and some students misused cohesive devices $[1,15,20]$. These findings imply that writing essays are uneasy, let alone writing argumentative essays since this genre requires the writer's capacity in using higher-order thinking skills $[8,10]$.

Some research has revealed that writing argumentative essays is challenging [18,24,29]. The arguments made by students were not strong even the rebuttal was rarely used [8], while some others show weak or no refutation [10] Meanwhile, a study by Wingate [29] to undergraduate students in London revealed that their ability in making argumentation was insufficient; their writings were lack of evidence and analysis. Similarly, an investigation by Stapleton and $\mathrm{Wu}$ [24] to high school students in Hong Kong on the argumentation quality in writing explanation essays revealed that the quality of reasoning was poor as they gave weak and even irrelevant reasons. Another possible reason that underlies students' difficulties in writing argumentative essays is lacking experience in writing academic texts in their first language [2,18]. To conclude, argumentative writing is challenging not only for native students but also for ESL and EFL students.

However, there is not much research investigating the quality of students' arguments in argumentative essays [12]. In fact, paying a closer look at the students' argumentation skills is essential as it can indicate which part they are still struggling with. Consequently, knowing the condition of students' argumentation skills may inform teachers to take proper actions to be implemented to help their students improve their argumentation skills. Given the importance of writing argumentative essays for students to fulfill academic tasks and express their critical thinking skills, there is a need to conduct research that investigates the quality of students' argumentation in their argumentative essays. It is necessary to find out the quality of students' argumentation skills since the quality of argumentation impacts the quality of the argumentative essays written by the students. Moreover, 
this investigation may reveal the condition of students' understanding of real-life issues and their abilities in providing arguments as well as convincing other people academically. Hence, the research question is formulated into "How is the quality of the argumentation written by the Academic Writing students in argumentative essays?"

\section{LITERATURE REVIEW}

Having argumentation skills is essential for students' academic life and social life. Argumentation skills are the manifestation of critical and higher-order thinking skills that is very crucial [21]. Hence, argumentation or the use of arguments plays a critical role in the development of critical thinking and in developing a deep understanding of complex issues and ideas [4]. These skills allow for the ability to analyze the sides of an issue and filter any information. In today's life where technology and social media are developing very fast, there is much information that students read or listen through social media. In order to be not misled by the information, they should have the ability to think critically before making any decision [21]. Furthermore, schools and universities graduates are required to possess critical thinking skills in addition to social skills and collaboration skills to face future careers in any employment $[3,7,10,22]$.

Argumentation skills in the context of English language learning are reflected through essay writing with particular genre argumentative essay. A good argumentative essay contains strong argumentation which convinces the readers that the writer's assertion is true [8]. To do this, the writer should give strong reasons why he proposes such claims. If the essay does not contain appropriate evidence that supports the writer's claim, the essay loses its purpose to convince the readers and thus is considered unreliable [6]. Toulmin's model of argument serves as a comprehensive approach to assessing validated bases of argument [27]. Toulmin views that proposing an argument is a cognitive process of problem-solving in which the goal is to convince the reader to change their initial position and follow the writer's position. Toulmin model is useful to develop the argument as it gives the basic layout for argumentation which can help the students-writers to develop ideas to be transformed into a complete argument [8].

Toulmin conceptualizes an argument as a claim that is supported by data with a warrant as to the connection [30]. In Toulmin's model of argumentation, there are six interrelated elements which include a claim, data (evidence), the warrant, backing, qualifier, and rebuttal. Figure 1 shows the six elements and the relationship.

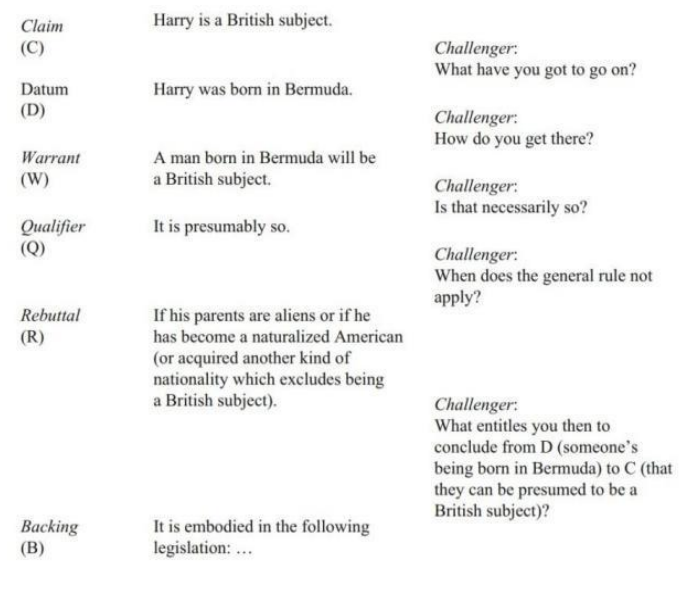

Source: van Eemeren et al. (2014)

Figure 1. Toulmin's Elements of Argumentation

In writing an argumentative essay, a writer needs to propose a claim as an attempt that justifies the assertion that has been made. The claim can be challenged; therefore, it should be backed up by supporting grounds [26] that are warrant. Similarly, making a claim could be the equivalent of writing a thesis as the activity of giving an argument [13] The warrant is strengthened by backing to increase the validity of the warrant and thus affect the validity of the claim [8]. The data or evidence given to support the claim can be in the form of facts, observations, statistical data, previous conclusions, and other specific information or texts $[27,30]$.

Studies have been carried out pertaining to assessing arguments. In a study by Heitmann, Hecht, Schwanewedel and Schipolowski [7] involving 3,274 German students revealed a moderate relation between argumentation and reasoning in their argumentative writings. The study confirmed that students with a high level of ability in argumentation in first language education also have a high level of ability in argumentation in the science field. However, the findings showed that most students did not produce counterarguments; they produced a one-side argument. Another study by Januin and Osman [8] investigates students' argumentation skills by using the Toulmin model of assessment. The study figured out that students' writings did not contain rebuttal although their argumentation was good. In fact, in making the argument, one not only gives information on the topic and states his claim but also gives evidence to the said topic and recognize the other's side as the counterarguments [17,22] Research show that essays that are focused on the topics and tend to show a relatively strong forceful voice of the writers can be considered succeeded in the proposition of their claim [28]. 
Table 1. Scoring Rubric with Toulmin's Criteria of Argumentation

\begin{tabular}{|c|l|l|}
\hline Elements & Rating & \multicolumn{1}{|c|}{ Description } \\
\hline Claim & 6 & Clear and complete generalization related to proposition. \\
& 4 & $\begin{array}{l}\text { The reader must infer the writer's intent; enough information is provided } \\
\text { that generalizations are related to the proposition. }\end{array}$ \\
& 2 & The writer's assentation is neither clear nor specific although the \\
& & generalization is related to proposition/ topic. \\
\hline Data & 6 & There is no claim for the proposition/topic. \\
\hline Opposition & 4 & The supporting data is not complete even though relevant. \\
& 2 & The data offered is weak, inaccurate, or incomplete. \\
& 0 & There is irrelevant or no data offered. \\
\hline Refutation & 4 & A systematic opposition is identified. \\
& 2 & An opposing argument is identified but not specific. \\
& 0 & There is some offering of opposition but not specific. \\
& 6 & There is no recognition of opposition offered. \\
\hline & 4 & A systematic opposition and opposing arguments identified. \\
& 2 & Counterarguments are present but not related to the opposition. \\
\hline & 0 & There is a weak denial of opposition claims. \\
\hline
\end{tabular}

Some research focused on improving students' abilities in writing argumentative essays by implementing certain teaching approaches [2,3,5,9,11,14,22]. Meanwhile, some studies investigate students' ability and problems in writing argumentative essays [11,23]. Eventually, these studies tried to aid instructors and students in facing difficulties in writing argumentative essays. As revealed in the study by Rashtchi [22], the students improved their argumentative writing skills in terms of originality, clarity, organization, and reasoning after they are taught using the reader-response approach to build their higher-order thinking skills. This study infers the need to facilitate students to practice their

Table 2. Categorization of Students' Argumentation Quality

\begin{tabular}{l|l}
\hline $\begin{array}{l}\text { Criteria of Grade } \\
19-24\end{array}$ & Grade \\
\hline $13-18$ & Gery Good \\
\hline $7-12$ & Fair \\
\hline $0-6$ & Poor \\
\hline
\end{tabular}

critical thinking skills through literature reading before they write argumentative essays. This means that having adequate knowledge on a topic and having a good ability in thinking to shape their ability in reasoning.

\section{METHOD}

This research was descriptive quantitative research that described the factual condition of students' argumentation skills. The subjects of the research were 30 students in intact classes of Academic Writing course of English Language Study Program of Universitas Lambung Mangkurat. The instruments were writing prompts and a scoring rubric. The scoring rubric was developed based on Toulmin's criteria for argumentation which consisted of claim, evidence, opposition, and refutation. Inter-rater reliability was employed to ensure the reliability of the data.

The data was then analyzed quantitatively and categorized into very good, good, fair, and poor quality of the argumentation. Then, the data was confirmed with the analysis on students' essays focusing on the quality of the claim, evidence, opposition, and refutation.

\section{RESULT AND DISCUSSION}

The data were obtained from the argumentative essays written by the students in the first task and the second task. The detailed findings are elaborated on below.

\subsection{Findings on the Use of Claim}

The findings showed that the claim proposed by the students in the first task was good as there were 20 out of 30 essays $(66.66 \%)$ that were categorized as very good wherein $66.66 \%$ of students gave "a clear and complete" claim. Meanwhile, eight essays were good of which $26.66 \%$ of the essays gave "enough information". Finally, two essays were average wherein $6.66 \%$ of students' claims were considered as "lack of specificity". Figure 2 displays the graph of the use of claims in the first task. 


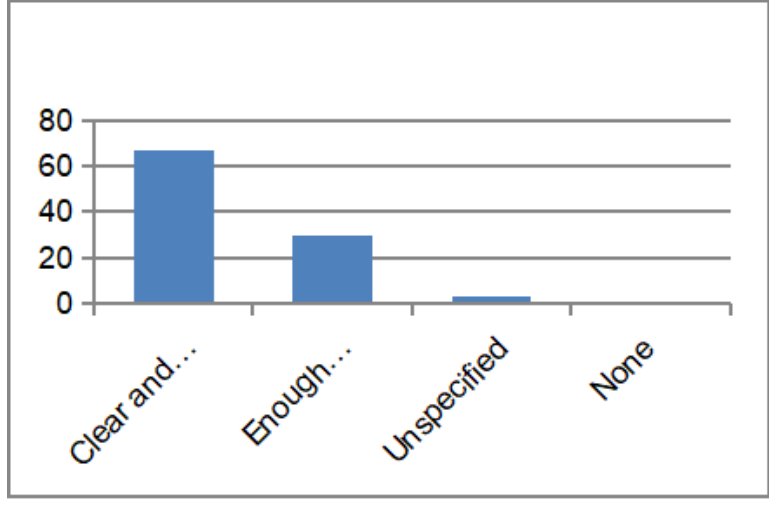

Figure 2. The Use of Claim in the First Task

Meanwhile, the findings on the second task revealed that the claim proposed by the students was also good as 20 essays were categorized as very good wherein $66.66 \%$ of students gave a "clear and complete" claim. Next, nine essays were good in which $30 \%$ of students gave "enough information". Finally, one essay was average as the claim was considered as "lack of specificity". Figure 3 displays the use of claims in the second writing task.

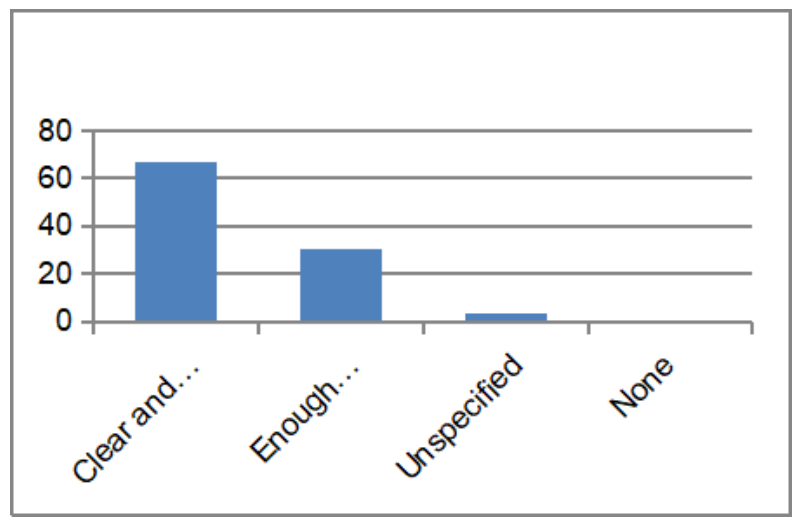

Figure 3. The Use of Claim in the Second Task

To illustrate the category of a very good claim and a poor one, the following are the samples of students' claims that are categorized as a very good claim and a poor claim.

\subsubsection{Samples of Good Claim}

"Thesis writing can be considered as an example of a piece of work that has been done by students. Students as academics will be considered as such by their contribution to the academic field. When students have been able to write scientific papers and are able to be held accountable in scientific examinations by a team of examiners who are experts in their fields, of course, this shows that the student is competent in his/her scientific field. Therefore, Thesis writing can be considered as a test for the student to show his/her competence in the academic field". (Task One)

"The working world will present us with various challenges that were never taught in college. For instance, the workforce gave an opportunity to practice and develop our expertise in certain fields such as making project plans, setting deadlines, a collaboration between teams. All of these experiences will forge our soft skills and give us new enthusiasm to reach our life goals." (Task Two)

\subsubsection{Samples of Poor Claim}

"Thesis is very important because it is proof of student work. Students should be able to complete it without having to find an easy way to finish his degree." (Task One)

"People choose the workforce as a way to feed themselves. They would not afford to continue to master degree and they choose to find a job for a living." (Task Two)

As seen in the samples, a good claim contains a generalization to the proposition while a poor claim is unclear.

\subsection{Findings on the Evidence Proposed in the Essays}

The analysis on the first task showed that 18 out of 30 essays were categorized as very good wherein $60 \%$ of the essays gave 'complete, accurate and related' evidence. Next, 11 essays were categorized as good wherein $36.66 \%$ of the essays gave 'related but not complete' evidence. Then, there were three essays that were categorized as average wherein $10 \%$ of students gave 'weak, inaccurate and incomplete' evidence, and one essay was categorized as poor because it did "not give any data". Figure 4 shows the use of evidence in students' writings on the first writing task.

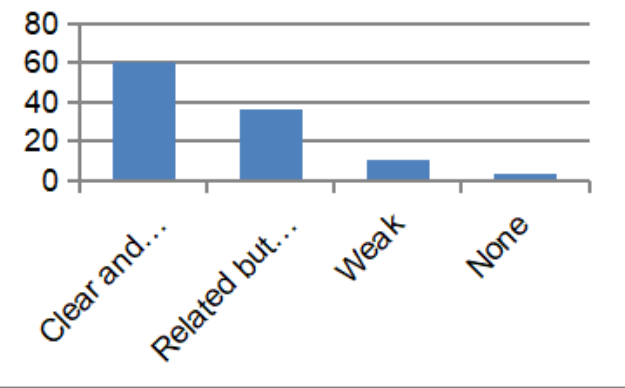

Figure 4. Use of Evidence in the First Task 
There was a slight difference on the second task in which 15 essays were categorized as very good since $50 \%$ of the essays gave 'complete, accurate and related' evidence. Meanwhile, nine essays were categorized as good because $30 \%$ of the essays gave 'related yet incomplete evidence'. Then, five essays were categorized as average wherein $16.66 \%$ of the essays gave 'weak or inaccurate' evidence, and the rest of the essays $(3.33 \%)$ did not give any evidence. The following figure displays the use of evidence in students' writings on the second task.

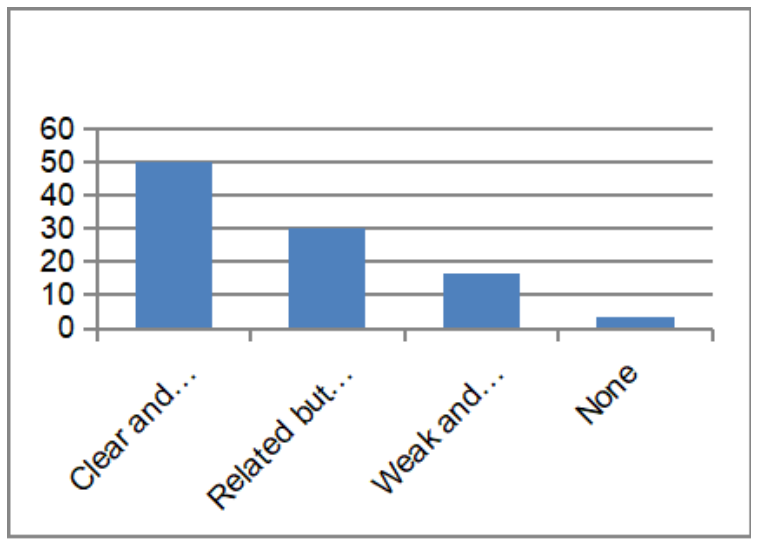

Figure 5. Use of Evidence in the Second Task

The following samples show students' evidence that is categorized as a very good evidence and a poor evidence.

\subsubsection{Samples of Good Evidence}

"There are several examples that could show why writing a thesis should still be a requirement. First, students from college to graduation must face scientific activities. First, because students' memory is very limited, scientific writing is an accurate tool to record all scientific events and arguments experienced by students themselves. When students are weak in remembering, scientific writing is the solution. Next, scientific writing is tantamount to building human civilization. What happened in the past can only be known because there is writing. Even the literacy culture that is now being heralded is almost certainly useless without the support of reading and writing behavior. This is also in tune with what our first President said "Don't forget the history", as even with a small thesis paper, students who write their thesis could make history. "(Task One)

"If someone hiring an engineer, the person wants someone with engineering training and project experience. Therefore, the company is not interested in someone with a Master's degree and a thesis. Even though, the thesis is an independent project that is related to the engineering that might be related. The company would not really take that into account if the person could not prove his/her skills. As a Mechanical or Aero-Astro undergrad, one learns lots of different things. But jobs typically focus on only a few. Therefore, your Master's gives you a little more focus towards the job in question." (Task Two)

\subsubsection{Samples of Poor Evidence}

"Thesis writing must not be the only way for passing the undergraduate program. Every student has their own advantages and weakness. For example, we can look at examples from abroad that have some universities provide a way for student graduates like mastering a certain course. This is helpful for students who are not good at writing." (Task One)

"It depends on the field. Some career options may require a Master's degree. Others, like software development, may prefer relevant work experience." (Task Two)

The samples show that a very good evidence is complete, accurate, and related to the topic. Meanwhile, a poor argumentative essay does not contain any evidence and thus the writer's argument is not convincing.

\section{3. Findings on the Use of Opposition}

The study revealed that the oppositions appeared in six essays (20\%) were 'systematic identification', eight essays $(26.66 \%)$ were 'incomplete identification', four essays (13.33\%) were 'not specific', and 12 essays (40\%) did not offer any opposition to the claim. Figure 6 shows the use of opposition in the students' essays in the first task.

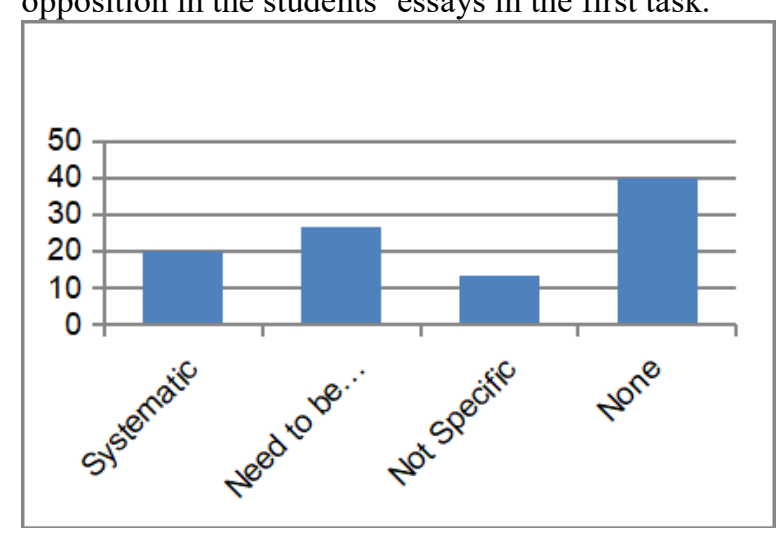

Figure 6. Use of Opposition in the First Task

Similarly, the second writing task also showed that the use of opposition is also low: five essays $(16.66 \%)$ gave systematic opposition, nine essays (30\%) showed that the opposition 'needed to be inferred', ten essays $(33.33 \%)$ showed that the opposition was not specific, and six essays (20\%) showed that there was not any opposition offered. Hence, the result indicated that the use of opposition 
was still low. Figure 7 displays the use of opposition in the students' essays in the second writing task.

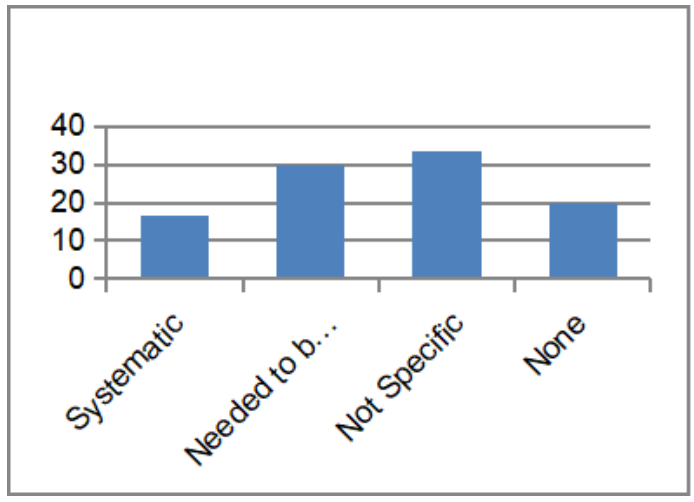

Figure 7. Use of Opposition in the Second Task

The following samples show students' oppositions that are categorized as a very good opposition and a poor opposition.

\subsubsection{Sample of Good Opposition}

"Although we must also admit that there are few students who still consider that "scientific writing" is limited to subjects or learning materials only. Therefore, it is not worth to be taken as a requirement to graduate from an undergraduate program. (Task One)

"Some study might find that employers believe that applicants with a college degree are more "job-ready" than those without a degree. However, at the same time, employers also admit that possessing a college degree does not guarantee that a candidate will be any better at the job than someone without a degree." (Task Two)

\subsubsection{Sample of Poor Opposition}

"Some people may think there must be another choice that students could take for finishing study. So, it is important to accommodate those people with certain hope." (Task One)

"Some people also have the mindset of getting a master degree will give them a higher initial income, yes no doubt it is true but why do you need higher income when you are not contributing anything?" (Task Two)

As seen in the samples, a good opposition is identified as the opposing argument whereas poor writing does not provide any recognition to the opposing argument.

\subsection{Findings on the Use of Rebuttal}

From the analysis, only one student scored 6 , four students scored 4 , six students scored 2 , and the rest scored 0 . To be specific, $3.33 \%$ of the essays gave "systematic rebuttal", $13.33 \%$ of the essays gave a "refutation that still needs to be inferred", $20 \%$ of the essays gave "vague reference and weak denials" and $63.33 \%$ of the essays did not give any refutation. Figure 8 shows the summary of the findings on the use of rebuttal in the students' essays on the first writing.

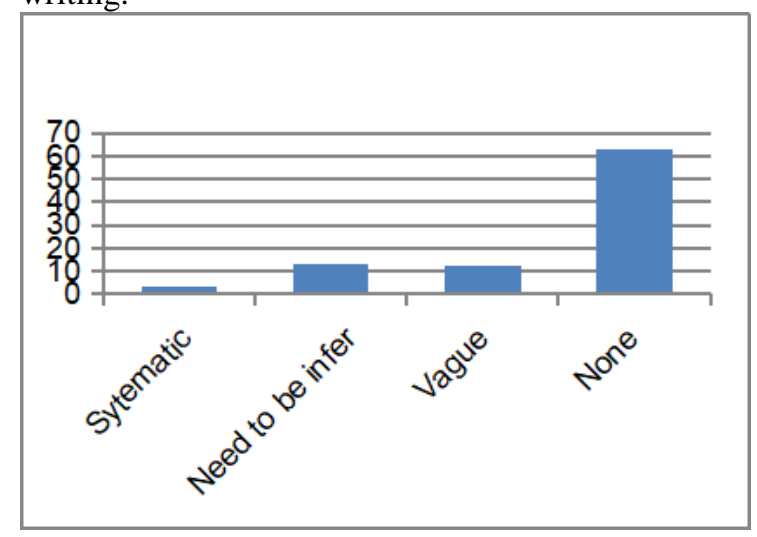

Figure 8. Use of Refutation in the First Task

The data on the second writing showed that there was only one student scored 6 , four students scored 4, seven students scored 2 , and the rest scored 0 . In other words, $3.33 \%$ of the essays gave systematic refutation/rebuttal, $13.33 \%$ of the essays gave a refutation that needed to be linked, $33.33 \%$ of the essays gave vague or weak denials, and $50 \%$ of the essays did not give any refutation. Therefore, from the four elements, refutation was the most poorly used. Figure 9 shows the use of rebuttal in the students' essays on the second task.

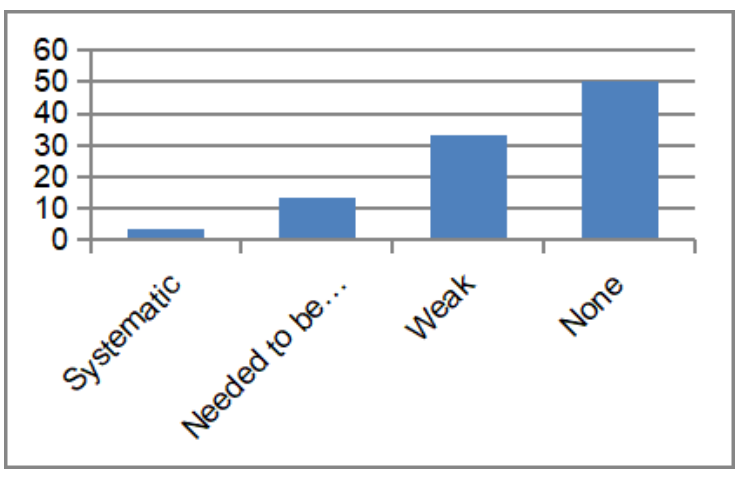

Figure 9 Use of Refutation in the Second Task

The following samples show students' claims that are categorized as a very good evidence and a poor evidence.

\subsubsection{Samples of Good Rebuttal}

"Although we must also admit that there are few students consider Thesis writing to be limited to subjects or learning materials only. Therefore, it is not 
worth to be taken as a requirement to graduate from an undergraduate program. Scientific Writing is an expression of ideas in writing that meet the rules of logical thinking. Therefore, the use of thesis writing as part of the requirement to graduate is part of the evidence whether the student who writes has already competent in writing scientifically or not. Moreover, this requirement will also differentiate between a student who is worthy for Bachelor's degree and a student who has yet to be competent enough in the field. In this sense, the competency of students who could not complete thesis writing is supposed to be questioned." (Task One)

"The study found that employers believe that applicants with a college degree are more "job-ready" than those without a degree. However, at the same time, employers also admit that possessing a college degree does not guarantee that a candidate will be any better at the job than someone without a degree. For example, employers feel that productivity levels are no different between degreed and non-degreed employees and that retention rates remain the same between workers with and without degrees. Even though employers note that having a degree doesn't guarantee a candidate will be a "better" employee, some companies still require that applicants have their degree." (Second Writing)

\subsubsection{Sample of Poor Rebuttal}

"There is no other alternative that could replace thesis writing as part of the requirement to finish an undergraduate program. Thesis writing shows the mastery of the field that student's study." (Task One)

"People should get the job first, do your best then you demand your wage rates. Getting a master's degree is a good thing when you get a job. It is no use that you are doing research and doesn't apply it". (Task Two)

The samples provide evidence that a very good rebuttal acts as a counterargument whereas poor writing does not propose any counterargument. Those samples illustrate the quality of the essays in terms of the claim, evidence, opposition, and rebuttal.

The findings were interpreted by categorizing them into very good, good, fair, and poor criteria. The students' argumentation skills which were categorized as 'very good' showed that they gave a clear and complete claim that was related to the topic of the essay. The result is similar to a study by Wijitsopon [28] that essays that are focused on the topics and tend to show a relatively strong forceful voice of the writers can be considered succeeded in the proposition of their claim. Even though the main focus of the research is the use of multi-word expressions on EFL students' essays, the results showed that clear and systematic use of the claim gives a strong assertion. Similarly, a claim can be considered as a justification that has been provided with good reason in order to persuade others. Therefore, a writer's claim needs to be clearly and strongly stated to make the readers convinced. Moreover, a claim is supposed to be in line with logical proof or empirical evidence [27].

In the same line, when anyone embarks on an argument, he proposes a claim that acts both as a starting point and the destination of the topic [25]. Therefore, a claim must be clear and systematically organized to fulfill those roles. Likewise, making a claim could be the equivalent of writing a thesis as the activity of giving an argument; a shape might be understood as a form of organizing [13]. In a nutshell, a claim should be clear and organized as it will show the writer's proposition.

In terms of evidence, students who obtained a 'very good' score proposed clear, complete, and accurate evidence. The accurate and strong evidence did not only enhance the writer's argument but also reduced the possible skepticism on the statement. This result confirms the theory that a writer cannot consider a claim as a matter of opinion as there must be supporting evidence to validate the claim [6]. In this way, the writer's claim is validated by the accurate evidence proposed. Among the students who got the 'very good' score, all of them gave opposition. This means that acknowledging opposing views by giving opposition can show that the writer is knowledgeable and thus contributes to the quality of the argumentation.

Rebuttal was another component evaluated in the students' essays. The findings showed that the majority of the essays did not provide rebuttal and many were weak as the writers did not support the refutation with convincing reasons. A rebuttal should be supported with good reasoning that precisely correlates to the writer's data, claims, warrants, and conditions of rebuttal. If these criteria have not been fulfilled, it can lead to confusion that would cause some trouble for the argumentation [26]. However, the findings of this study revealed that the majority of the subjects did not give refutation to the opposition. This finding is similar to the findings of the research conducted by Heitmann and Khodebande [7,11] wherein the subjects also did not provide refutations in their essays. Hence, these studies indicate that proposing opposition and refutation in writing argumentative essays is hard for EFL students. Further investigation is needed to confirm the causes of this phenomenon.

Based on the analysis, the students who achieved a 'good' score provided a claim that was considered clear and complete. Meanwhile, some other students gave an incomplete yet related claim. Moreover, there was one student who gave a weak statement of the claim but achieved a 'good' score because the evidence, opposition, and refutation that had been given are considered as good. This proved that if the claim is to be accepted as a solid and reliable one, the person who proposes it must give a solid underlying foundation [26]. As shown in Table 2 , it is possible that even though the claim is not very 
good, but the evidence, opposition, and refutation given in the essay are considered good, and if the scores were calculated, the student obtained a 'good' score. Therefore, strong supporting data/evidence given could convince readers to believe the claim that at first can be considered weak. The finding also confirms the theory that evidence is an important tool to rationally persuade others of our beliefs and opinions [6].

The findings also showed that there were twelve students $(40 \%)$ who were categorized as fair in terms of their argumentation in the first writing. The result is different from the findings on the second writing in which $60 \%$ or 18 students were categorized as fair. Most of the essays gave claims and evidence, but only some of them gave opposition and refutation. This is similar to the finding from the research of Qin and Karaback [19] on Chinese EFL writing students. In their study, one subject did not give any opposing argument or refutation on the essays. However, the student's argumentation achieved a fair score because the student gave a 'clear and complete' claim that its words were organized systematically to convince the reader. The student also gave complete and clear supporting evidence related to the statement afterward. Therefore, even though the essay did not provide any opposition and refutation, the argument of the essay could be considered as good because of the very good claim and supporting data gave by the writer. A similar finding had also been encountered by Nopita [16] in her research on Indonesian EFL writing students. The research found that students who obtained fair scores did not propose a justification for the claims. Nonetheless, the students' essays were not categorized as poor because the scores of other aspects are considered as good.

Finally, the findings revealed that there was one student who obtained poor scores both in the first and the second writing. In the essay, the writer had a 'good' claim. However, there was no evidence, opposition, and refutation to support the claim. This proves that even a strong statement of claim alone is not enough to convince the reader to agree with the writer's argument. Similarly, a study by Stapleton and Wu [24] also found that essays that were written by students without enough evidence nor relevant reasons were considered poor quality of argumentation. In the same line, research by Wingate [29] also revealed that among the low achieving essays, the most apparent problem was the lack of evidence. As stated by Toulmin [26] a claim that is to be accepted as solid and reliable, the person who proposed it must give a solid underlying foundation. Therefore, Toulmin's theory on evidence is confirmed by these findings.

\section{CONCLUSION}

Referring to the analysis of argumentation elements on both the first and second writings showed that students' skill in using claims and data is satisfying.
It is found that on both writings, $66.66 \%$ of students gave complete and clear claims. For the use of data, it is found that $60 \%$ of students gave clear and complete data on the first writing and $50 \%$ on the second writing. However, the students' skill in using opposition and refutation is not satisfying enough. Some students did not propose any opposition; there are $40 \%$ students on the first writing and $20 \%$ students on the second writing that did not propose any opposing argument. Furthermore, $46.66 \%$ of the students on the first writing and $50 \%$ students on the second writing did not give any refutation. There is a possible reason why the opposition and refutation scores were categorized as low. Since the nature of this research was impromptu, there is a possibility that the students did not possess sufficient background knowledge on the topic that they were asked to write on the essay. Consequently, they had trouble in opposing the other side. This brings implications that more practices on acknowledging opposing view and providing refutation is needed to facilitate students develop their argumentation skills. Further research is also recommended involving more subjects and different methods of analysis to obtain more comprehensive findings.

\section{AUTHORS' CONTRIBUTIONS}

The first author originated and formulated the study. Then, all the authors examined properly and agreed on the main issue and ideas of the study. Eventually, all authors made equal participation and contributions to the writing of this article.

The first proof-of-concept was completed by the first author and then expanded by the second and third authors. In brief, the first author is responsible for the research design and data analysis. Meanwhile, the second author is in control of literature review and data collection, and the third author is in charge of formatting and grammar checking of the final draft of this article.

Finally, all authors validated the final version of the article and are liable for the content.

\section{ACKNOWLEDGMENTS}

The authors thank, in particular, Mohammad Yamin, M.Pd, Fitria Kamelia, M.Pd, and Rizki Amelia, M.Pd for the assistance in evaluating students' essays and useful suggestions for the betterment of the scoring rubrics and writing prompts. In addition, the authors wish to acknowledge the anonymous individuals for their valuable insights, support, and contribution to the quality of this article.

\section{REFERENCES}

[1] A.Ariyanti, R. Fitriana, EFL Students' Difficulties and Needs in Essay Writing. Advances in Social 
Science, in: Proceedings of Education and Humanities in Social Science, Education, and Humanities Research (ASSEHR), vol. 158, 2017, 158, pp. 111-121. DOI https://doi.org/10.2991/ictte$\underline{17.2017 .4}$

[2] J.A. Butler, M.A. Britt, investigating instruction for improving revision of argumentative essays, in: Proceedings of Written Communication, vol. 28, 2011, pp. 70-96. DOI: https://doi.org/10.1177/0741088310387891

[3] K. Changwong, A. Sukkamart, B.Sisan, Critical thinking skill development: Analysis of a new learning management model for Thai high schools, in: Proceedings of Journal of International Studies, vol. 11, 2018, pp. 37-48. DOI: https://doi.org/10.14254/2071-8330.2018/11-2/3

[4] P. Deane, Y. Song, A case study in principled assessment design: Designing assessments to measure and support the development of argumentative reading and writing skills, in: Proceedings of Psicología Educativa, vol. 20, 2014, pp. 117-123. DOI: http://dx.doi.org/10.1016/j.pse.2014.11.006

[5] M. Fahim, P. Hashtroodi, The Effect of Critical Thinking on Developing Argumentative Essays by Iranian EFL University Students, in: Proceedings of Journal of Language Teaching and Research, vol. 3, 2012, pp. 632-638. DOI: https://doi.org/10.4304/j1tr.3.4.632-638

[6] T. Govier, A Practical Study of Argument, Wadsworth CENGAGE Learning, 2010.

[7] P. Heitmann, M. Hecht, J. Schwanewedel, S. Schipolowski, Students' Argumentative Writing Skills in Science and First-Language Education: Commonalities and differences, in: Proceedings of International Journal of Science Education, vol. 36, 2014, pp. 3148-3170. DOI: https://doi.org/10.1080/09500693.2014.962644

[8] J. Januin, W.H. Osman, Analysing ESL Persuasive Essay Writing Using Toulmin's Model of Argument, in: Proceedings of Psychology and Education Journal, vol. 58, 2021, 1810-1821. DOI: https://doi.org/10.17762/pae.v58i1.1034

[9] J. Jumariati, G. Sulistyo, Problem-Based Writing Instruction: Its Effect on Students' Skills in Argumentative Writing, in: Proceedings of Arab World English Journal, vol. 8, 2017, 87-100. DOI: https://doi.org/10.24093/awej/vol8no2.6
[10] M. Ka-kan-dee, S. Kaur, Teaching Strategies Used by Thai EFL Lecturers to Teach Argumentative Writing, in: Proceedings of Social and Behavioral Sciences Vol. 208, 2015, DOI: https://doi.org/10.1016/j.sbspro.2015.11.191

[11] F. Khodebandeh, M. Jafarigohar, H. Soleimani, F. Hemmati, Investigating Iranian EFL writing problems and examining back transfer, in: Proceedings Asian EFL Journal, vol.16, 2005, pp. 227-270.

[12] D. Kuhn, W. Udell, The Development of Argument Skills, in: Proceedings of Child Development, vol. 74, 2003, pp. 1245-1260. DOI: https://doi.org/10.1111/1467-8624.00605

[13] A. Lunsford, J. John , Ruszkiewicz, Instructor's Notes for Everything' s an Argument (7th ed.), Bedford/St. Martin's A Macmillan Education Imprint, 2016.

[14] N. Nejmaoui, Improving EFL Learners' Critical Thinking Skills in Argumentative Writing, in: Proceedings of English Language Teaching, Vol. 12, 2018, pp. 98. DOI: https://doi.org/10.5539/elt.v12n1p98

[15] M.A. Nindya, U. Widiati, Cohesive devices in argumentative essays by Indonesian EFL learners, in: Proceedings of of Journal on English as a Foreign Language, vol. 10, 2020, pp. 337-358. DOI: https://doi.org/10.23971/jefl.v10i2.1949

[16] I. Nopita, I, Exploring Efl Students' Critical Thinking in Writing Analytical Exposition Text: an Sfg- Based Analysis, in: Proceedings of English Ideas: Journal of English Language Education, Vol. 1, 2020, pp. 28-39.

[17] E.M. Nussbaum, Argumentation, dialogue theory, and probability modeling: Alternative frameworks for argumentation research in education, in: Proceedings of Educational Psychologist, Vol. 46, 2011, 84-106. DOI: https://doi.org/10.1080/00461520.2011.558816

[18] J. Peloghitis, Difficulties and strategies in argumentative writing: A qualitative analysis review of the literature, in: Proceedings of Transformation in Language and Education, 2016, pp. 399-406.

[19] J. Qin, E. Karabacak, The analysis of Toulmin elements in Chinese EFL university argumentative writing, in: Proceedings of System, Vol. 38, 2010, pp. 444-456.DOI: https://doi.org/10.1016/j.system.2010.06.012

[20] T. Rahayu, B.Y. Cahyono, Discourse Markers in Expository Essays Written by Indonesian Students of EFL, in: Proceedings of International Journal of 
Language and Linguistics, vol. 2, 2015, pp. 2129.

[21] C. Rapanta, C, M. Garcia-Mila, S. Gilabert, What Is Meant by Argumentative Competence? An Integrative Review of Methods of Analysis and Assessment in Education, in: Proceedings of Review of Educational Research, Vol. 82, 2013. DOI: https://doi.org/10.3102/0034654313487606

[22] M. Rashtchi, Scaffolding argumentative essay writing via reader-response approach: a case study, in: Proceedings of Asian-Pacific Journal of Second and Foreign Language Education, vol.4, 2019. DOI: https://doi.org/10.1186/s40862-0190078-2

[23] J. Soland, L.S. Hamilton, B.M. Stecher, Measuring 21st century competencies: Guidance for educators, in: Proceedings of Asia Society Global Cities Education Network Report, vol. 68, 2013, http://asiasociety.org/files/gcenmeasuring21cskills.pdf

[24] P. Stapleton, Y. Wu, Assessing the quality of arguments in students' persuasive writing: A case study analyzing the relationship between surface structure and substance, in: Proceedings of Journal of English for Academic Purposes, vol. 17, 2015, 12-23. DOI: https://doi.org/10.1016/j.jeap.2014.11.006

[25] S. Toulmin, R. Rieke, A. Janik, An introduction to reasoning (2nd Ed.), Macmillan Publishing, 1984.

[26] S. Toulmin, The Uses of Argument, Cambridge University Press, 2003. DOI: https://doi.org/10.1017/CBO9780511840005

[27] F.H. Van Eemeren, B. Garssen, E.C.W. Krabbe, A.F.S. Henkemans, B. Verheij, J.H.M. Wagemans, Handbook of Argumentation Theory. Springer Reference, 2014.

[28] R. Wijitsopon, Key multi-word expressions in Thai learner English argumentative essays, in: Proceedings of The Asian EFL Journal, vol. 23, 2019, 23, pp. 115-141.

[29] U. Wingate, U. "Argument!" helping students understand what essay writing is about, in: Proceedings of Journal of English for Academic Purposes, vol. 11, 2012, pp. 145-154. DOI: https://doi.org/10.1016/j.jeap.2011.11.001

[30] C. R. Wolfe, Argumentation across the curriculum. Written Communication, vol. 28, 2011, pp. 193219.

DOI:

https://doi.org/10.1177/0741088311399236 